\title{
An Intermediary Organization Finds Potential Needs By Exploiting Serendipity
}

\author{
Akihiko Nagai, Nobutaka Odake \\ Nagoya Institute of Technology, Nagoya, Japan
}

\begin{abstract}
This paper intends to clarify the needs serendipity in creating new business. The authors will show that serendipity is capability method of finding potential needs and/or new markets. In economic society, potential needs and/or new markets are only partially exposed, such as an iceberg. Serendipity is a capability that can expose the potential hidden part through accidental opportunity. Something more concrete can be formed from the exposed parts. The authors describe cases that demonstrate the usefulness of serendipity. In one case, a high-tech start-up had intended to use medical electronic equipment and/or industrial electronic equipment as the first application of their core technology. In these markets, they were competing with established major companies, so this start-up had difficulty entering these markets. However, a specific distributor found potential needs that were met by the start-up's products, and has created a new market by combining their core technology with social needs. The authors define serendipity capability by analyzing this case example and argue that serendipity can contribute to finding opportunities and solving social issues.
\end{abstract}

Keywords: serendipity, intermediary organization, potential needs, search of facts, stock of knowledge

\section{Introduction}

A new business creation goes through five business phases: (1) start-up, (2) development, (3) improvement, (4) commercialization, and (5) success. As shown in Figure 1, the start-up phase involves finding an opportunity. The development phase realizes existing needs and visualizes potential but as yet invisible needs. The improvement phase meets those invisible needs. The commercialization phase creates a competitive advantage. Finally, the success phase structures an ecosystem around that advantage. The most important phases in starting a new business are the start-up through improvement phases. Finding a business opportunity and then solving the social issues inherent in that opportunity are particularly important to new business creation. However, this is very difficult.

This paper proposes serendipity as a capability. Serendipity exposes business opportunities and potential needs, solves potential needs, and creates competitive advantage. As shown in Figure 2, potential needs and/or new markets are only partially exposed and can be hidden behind the visible part. New business creation should look for the invisible part.

Akihiko Nagai, Ph.D. student, Graduate School of Engineering, Architecture, Civil Engineering and Industrial Management Engineering, Nagoya Institute of Technology, Nagoya, Japan.

Nobutaka Odake, Department of Techno-Business Administration, professor, Nagoya Institute of Technology, Nagoya, Japan.

Correspondence concerning this article should be addressed to Nobutaka Odake, Nagoya Institute of Technology, Gokiso-cho, Showa-ku, Nagoya, Aichi, 466-8555 Japan. E-mail: odake.nobutaka@ nitech.ac.jp. 


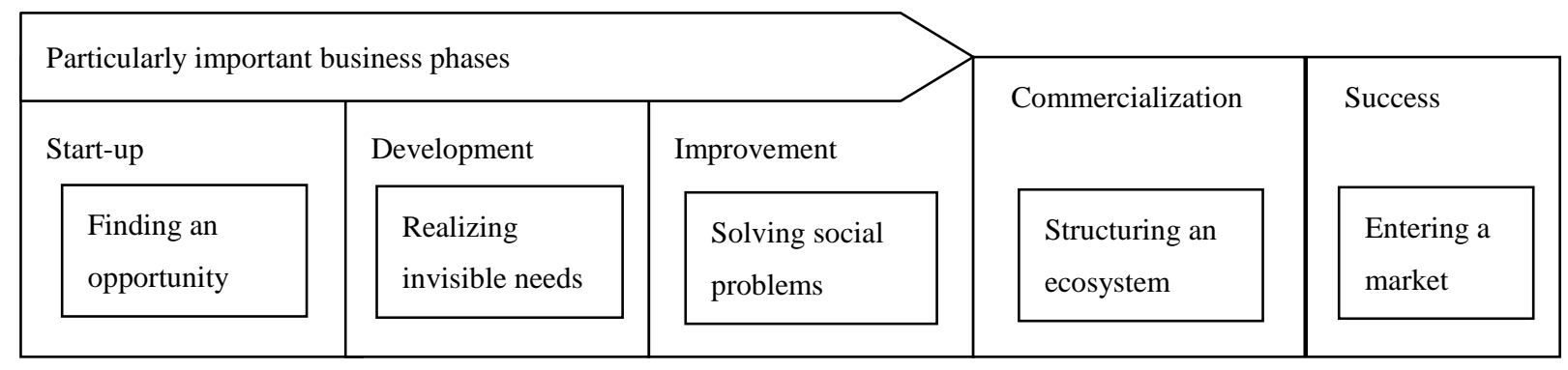

Figure 1. Business process.

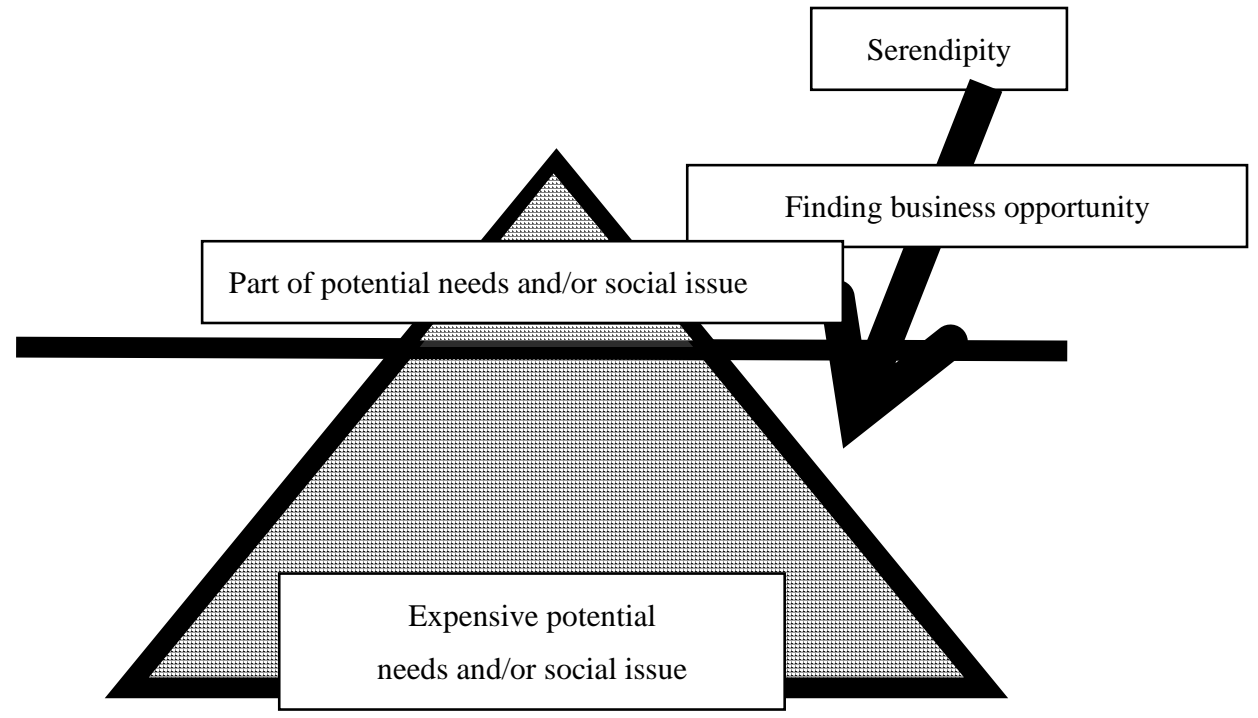

Figure 2. Potential needs and/or new market are exposing only part of it.

This paper is organized as follows: The next section, serendipity, indicates the position of this study through review of existing studies. The following section, existing research, explains how case studies are used as a research methodology. The case of graphic processing unit for digital pachinko section introduces a case study that shows the contribution that serendipity can make to exposing a new business opportunity. The discussion section reviews a case study that was outlined in the previous section and shows how a specific distributor found potential needs and/or new markets serendipitously. Final section summarizes the conclusions.

\section{Serendipity}

In this chapter, this paper explains serendipity as a capability. Serendipity is generally understood as the ability to find desirable things by accident, and can be construed as meaning intuitive inspiration that can be caught from lady luck (Ronald, 1985, pp. 282-285; Umberto, 1999; Sawaizumi, Shiose, Kawakami, \& Katai 2005; Cristiforo, 2000). In this paper, authors use serendipity to mean the capability of finding potential needs or invisible markets. That, combined with knowledge and information, it can lead to the formation of something more concrete. The effectiveness of serendipity through the phases of new business creation has never been sufficiently examined. This study focused on the start-up phase, the development phase, and the improvement phase, and discussed serendipity as a capability for continuing business efforts beyond these initial phases. 
Figure 3 presents a causal loop of serendipity in business creation. According to Nagai and Tanabe (2007, pp. 23-33; 2011, pp. 133-142), in general, distributors have specific functions (called FILM), and part of these distributors has generating new business exploiting FILM recently. This paper considers these specific functions as serendipity capability and suggests that specific intermediaries can carry out business creation beyond the usual business process by exploiting serendipity. Serendipity has two influences on business creation. First, serendipity reveals business opportunities. Second, serendipity exposes invisible needs and once those needs are met, solves social problems through feedback.

Specific intermediaries are carried out business creation beyond business process by serendipity capability.

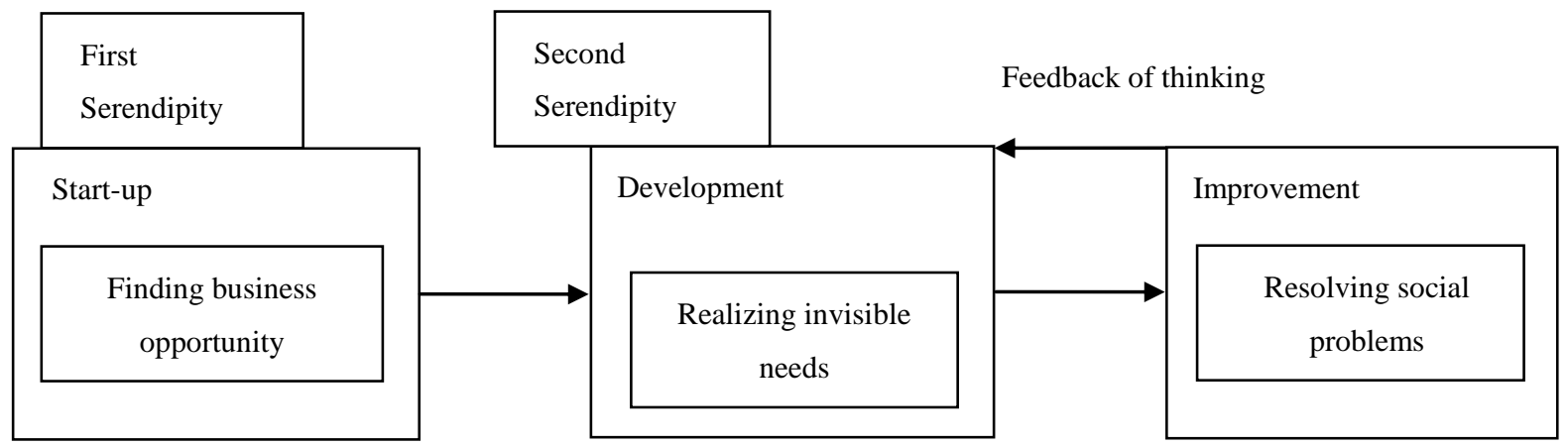

Figure 3. Causal loop of serendipity in business creation.

\section{Existing Research}

Other studies have concluded that the word "serendipity" derives from a letter written by Walpole (1754), referring to the fable "the pilgrimage of three princes of serendip". He used "serendipity" to mean the ability to find desirable things by accident (Remer, 1965). The concept of serendipity in the field of scientific research began to be used to explain a sociological method of the grounded theory (GT) by Merton (1949) and Merton and Elinor (2003). Serendipity was used to explain the occasion of developing a new theory or to extend an existing theory (Andel, 1994, pp. 631-648; Hannan, 2006; Roberts, 1989). Serendipity in GT is a systematic methodology of the social sciences and has a highly correlated factor for market creation (Glaser, 1967; Glaser \& Strauss, 1992; Martin \& Turner, 1986, pp. 141-157).

Additionally, Merton (1949) pointed out the similarity of serendipity and Kuhn's concept (1962) of paradigm shift. Kuhn (1962) argued that normal science does not contribute to scientific advances. This places more significance on unexpected findings of serendipity.

Table 1

Similar concepts of serendipity

\begin{tabular}{lllll}
\hline Concepts & Awareness/ring a bell & Search of facts & Stock of knowledge & Feedback of thinking \\
\hline Aha experience & $\circ$ & $\circ$ & $\circ$ & \\
Eureka & $\circ$ & & $\circ$ & $\circ$ \\
Serendipity & $\circ$ & $\circ$ & $\circ$ & 0 \\
\hline
\end{tabular}


It has been shown that serendipity is an accidental finding or inspiration and it has been suggested that serendipity is a capability that can reveal potential needs or invisible markets. However, serendipity can form something more concrete and it is not obvious as a capability that can combine with knowledge and information. Table 1 shows concepts that are similar to serendipity, including the "Aha experience" and "Eureka". According to Stein (1999), "Eureka" means the intuitive and/or accidental phenomenon of finding opportunity. According to Bühler (1990), the "Aha experience" has deep similarities to serendipity. On the other hand, these concepts have differences that don't take feedback into account.

\section{Research Method}

In this paper, the authors discuss the usefulness of serendipity through a case study. A case study is a useful method for abstracting the behavior of companies and organizations, therefore, it will be able to clarify the concept of serendipity as a capability (Eisenhardt, 1989, pp. 532-560; Eisenhardt, 1991, pp. 620-627; Eisenhardt \& Graebner, 2007, pp. 25-32).

According to Yin, qualitative studies like the case study are suited to explain empirical events. This paper is based on Yin's suggestion (1981, pp. 58-65; Yin, 1994). The authors interviewed many related parties about the same questions to get exact information and collected additional data from websites and documents.

\section{Case: Graphic Processing Unit for Digital Pachinko}

In this case study, a high-tech start-up combined their core technology with social issues and created a new business market. The contribution of a specific distributor plays a part in this. One distributor for this high-tech startup's products played an important role in finding potential needs and creating the new markets. Finding business opportunities is particularly important for high-tech start-ups, which find it difficult to uncover new opportunities as a rule. As described earlier, new business creation can take advantage of opportunities that were previously hidden. Exposing invisible opportunities needs strong ties (Granovetter, 1973, pp. 1360-1380) with the market and information collecting ability, the qualities a distributor can bring to the table.

\section{Fabless Semiconductor Start-ups}

Semiconductor high-tech start-ups (SHS) develop the ASSP (Application Specific Standard Products) with their core technology (Hamel \& Prahalad, 1990).

SHS base ASSP on their core technologies and sell to specific users (e.g. mobile phone manufacture firms, LCD (liquid crystal display) TVs manufacture firms). SHS don't have their own semiconductor factory and therefore must outsource ASSP mass-production to manufacturing firms called "semiconductor foundries". Foundry firms concentrate all of their capital and resources on semiconductor manufacturing facilities and specialize only in semiconductor manufacturing. Since the early 1990s, several fables semiconductor start-ups (FSS) have succeeded in the world market. The ASSPs of these FSS became the market standard (i.e. de facto standard $^{1}$ ) for limited application. ASSPs are developed and become available as versatile modules in contrast with ASICs (application specific integrated circuit) that were developed for a single specific user product. Actually, these ASSPs are used in specific electronics and automotive industry products. The ASSPs developed by these FSS have affected major Japanese electronics companies, which have promoted the use of ASSPs in their products and ended the use of ASICs in order to compete with the market power of other major electronics

\footnotetext{
${ }^{1} \mathrm{~A}$ de facto standard is a product or service that has got a dominant position in market.
} 
firms in the world. This phenomenon threatens major domestic semiconductor companies, yet could not give an opportunity for Japanese semiconductor start-ups to enter the market.

Indeed, in Japan, according to NEDIA (Nippon Electronic Device Industry Association) (JASVA Research Report, 2007), of more than 40 FSS companies established in the past, only four are listed on the stock exchange.

\section{Finding Business Opportunity}

In 1998, the pachinko industry experienced a critical issue. At the time, pachinko machines fed a passion for gambling. Pachinko generated a gambling habit, which led to social problems. This critical social issue led to a decreased population of pachinko users and caused severe damage to the pachinko industry. The pachinko industry felt that if they could change pachinko from a gambling machine to an entertaining game machine, they would be able to solve this problem. However, digital pachinko needed a new high performance graphics processing unit $(\mathrm{GPU})^{2}$ in order to create an entertaining pachinko machine. On the other hand, the leading semiconductor companies do not cooperate for new GPU development. Specific semiconductor distributor "A" realized that this situation presented a tremendous business opportunity to the pachinko industry. "A" realized that it would be possible to incorporate the core technology of SHS "B" to solve this critical issue. Subsequently, "B" developed a GPU for digital pachinko that exploits the technological advantage which they held in image processing of animation, and earns great benefit by it.

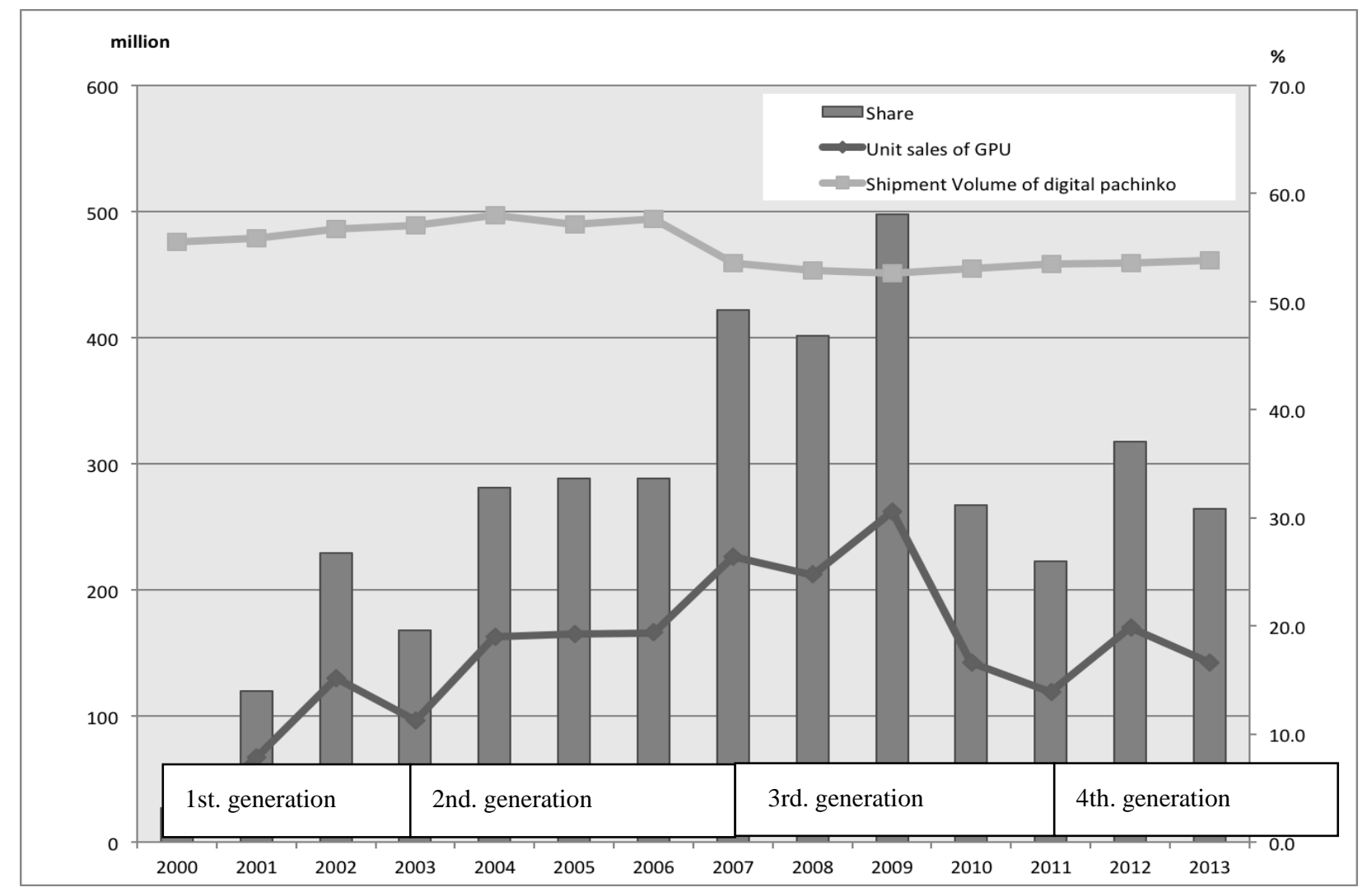

Figure 4. Changes in sales of GPU to net sales in SHS "B". Source: Graph based on the Axell Corporation. (2000-2013).

\footnotetext{
${ }^{2} \mathrm{~A}$ graphics processing unit is a specialized electronic circuit designed to rapidly manipulate intended output to a display.
} 
Company "B" is listed on the first section of the Tokyo stock exchange as a result of the success of this business. Company "B" has grown into one of the great semiconductor companies in Japan, and net sales have increased from $367,000,000$ yen in 2000 to $10,000,000,000$ yen or more in 2013 as shown in Figure 4.

So the contribution of a specific semiconductor distributor "A" to success of the SHS "B" can be seen. The development of a GPU for digital pachinko can be attributed to "A", which realized a potential market, exposed potential needs, and realized a solution to those needs.

\section{Exposing Potential Needs and Solving Them by Repeatedly Combining With Thought}

This section considers how the actions of semiconductor distributor "A" contributed to the serendipity capability of company "B". A serendipitously discovered business opportunity evolved into something more concrete by knowledge produced by a second serendipity. Specifically, semiconductor distributor "A" found a business opportunity that combined the core technology of a SHS by exploiting their own knowledge of the industry. " $\mathrm{A}$ " exposed potential needs that are entirely hidden behind visible needs and meet the need by collaborating with SHS "B" and with innovative pachinko firm "C" which possessed sticky information and knowledge. Potential needs, through collaborative thinking on the part of "B" and "C", are met by a causal loop between the parties' stock of knowledge and search for facts.

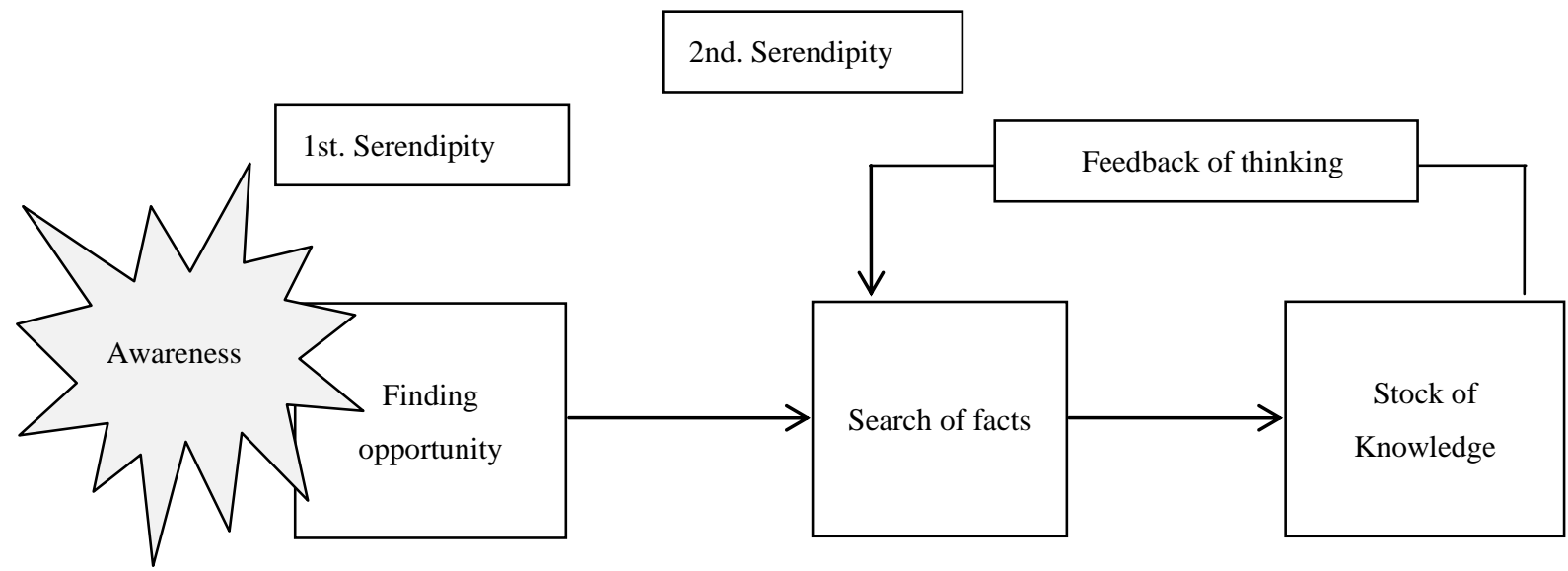

Figure 5. Causal loop of serendipity in business creation.

Figure 5 shows how opportunity is found through the first serendipity and is formed by the causal loop of the second serendipity. The authors' finding opportunity is the first serendipity. The authors define second serendipity as the effect of repeated loops of combining the opportunity with further thought. Potential needs or new business opportunities thereby turn into something more concrete.

The semiconductor distributor finds a GPU market in the pachinko industry as an opportunity to adapt core technology possessed by a high-tech start-up realizes entertaining animation of digital pachinko that satisfies invisible needs (existing needs).

Additionally, it exposed potential needs and gained a competitive advantage by solving social issues (potential needs). Realization of potential needs seems irrational but the facts are rational, and other rivals cannot imitate it. Table 2 indicates the competitive advantage that was gained by solving potential needs. 
Table 2

Competitive Advantage

\begin{tabular}{|l|l|}
\hline Irrationality (from without) & Rationality (from within) \\
\hline Do not realize the latest 3D graphic technology. & $\begin{array}{l}\text { 2D+ movie provides fully satisfactory performance for creation } \\
\text { of attractive animation. }\end{array}$ \\
\hline $\begin{array}{l}\text { Develop image compression technology for animation of digital } \\
\text { pachinko. }\end{array}$ & $\begin{array}{l}\text { MPEG (moving picture experts group) (Standard technology) is } \\
\text { not adequate to animation. }\end{array}$ \\
\hline GPU adopts the legacy semiconductor process technology. & $\begin{array}{l}\text { This is an effective way to develop LSI that is strong on static } \\
\text { noise. }\end{array}$ \\
\hline
\end{tabular}

Table 3

Semiconductor Process Technology

\begin{tabular}{|c|c|c|c|c|c|c|c|}
\hline \multicolumn{2}{|c|}{ Initial cost (Payment to foundry) } & \multirow{2}{*}{\begin{tabular}{|l} 
Very High \\
Cheap
\end{tabular}} & \multirow{2}{*}{$>$} & \multirow{2}{*}{$\begin{array}{c}\text { High } \\
\text { Reasonable }\end{array}$} & \multirow{2}{*}{$>$} & \multirow{2}{*}{$\begin{array}{l}\text { Small invisible } \\
\text { Very expensive }\end{array}$} & \multirow{2}{*}{$\begin{array}{l}\text { Selected } \\
\text { technology }\end{array}$} \\
\hline \multicolumn{2}{|l|}{ Cost } & & & & & & \\
\hline Year & Generation & \multicolumn{2}{|c|}{ Leading-edge } & \multicolumn{2}{|c|}{ Economic } & & Legacy \\
\hline 1999 & 1st. Generation & \multicolumn{2}{|c|}{$0.18 \mu \mathrm{m}$} & \multicolumn{2}{|c|}{$0.35 \mu \mathrm{m}$} & & $0.8 \mu \mathrm{m}$ \\
\hline 2002 & 2st. Generation & \multicolumn{2}{|l|}{$0.11 \mu \mathrm{m}$} & \multicolumn{2}{|c|}{$0.25 \mu \mathrm{m}$} & & $0.6 \mu \mathrm{m}$ \\
\hline 2006 & 3st. Generation & \multicolumn{2}{|l|}{$0.08 \mu \mathrm{m}$} & \multicolumn{2}{|c|}{$0.18 \mu \mathrm{m}$} & & $0.35 \mu \mathrm{m}$ \\
\hline
\end{tabular}

As shown in Table 3, the GPU does not adopt the most advanced semiconductor process technology, instead it adopted legacy process technology.

\section{Behavioral Process of Serendipity Capability}

The process of finding a new business opportunity occurred as follows: When SHS "B" and semiconductor distributor "A" met, they took up digital pachinko as a discussion theme. "A" suggested that if "B" could develop an ASSP for digital pachinko using existing core technology (image processing techniques), pachinko firms would be able to create compelling animation content. They made the case that this would be an excellent business opportunity.

This phenomenon is the first serendipity. Semiconductor distributor "A" quickly conducted market research with pachinko firms to learn whether or not market users want a high performance GPU in order to create entertaining animation content. From this survey, "A" found that pachinko manufacturers could not create entertaining content because digital pachinko uses same GPUs as home video game machines. In addition, they learned that pachinko firms do not enjoy the cooperation of major semiconductor companies because they see pachinko as a gambling industry (i.e. niche market). By matching the needs of the digital pachinko industry with the core technology of SHS "B", "A" revealed as new business opportunity and carried out the development of the GPU for digital pachinko. At the same time, "A" proposed co-development of a GPU for digital pachinko to the innovative pachinko firm "C". "A" provided iterative feedback by combining a search for facts and the stock of knowledge possessed by each company. If an idea is found by first serendipity, the idea will be researched based on fact and will combine stock of knowledge by second serendipity. This thinking process exposes potential needs and can determine how to meet them.

\section{Discussion}

\section{Reasons for the Semiconductor Distributor Exploiting Serendipity Capability}

The authors conducted interviews with each company in order to clarify the behavior of semiconductor distributor "A" as an intermediary organization and came to how it could provide a serendipity capability by 
interviewing stakeholders. "A" that possesses serendipity capability plays a key role as intermediary organization as follows. First, they assess the technology of the high-tech start-up "B" and collect information of industries and markets that they serve. "A" correctly understood that the core technology of "B" would be suitable for increasing the animation capabilities of digital pachinko. " $\mathrm{A}$ " collected information from the industry and combined it with an application for pachinko animation by learning that a new GPU was needed. This "finding of opportunity" is the first serendipity capability.

The second function is the capability of exposing potential needs that are entirely hidden behind the visible part and to form them into more concrete needs by exploiting information. " $A$ " can give feedback by searching out facts and utilizing its own stock of knowledge of each company. If an idea is found by first serendipity, it will be further researched based on fact and its stock of knowledge. This process exposes potential needs and can determine how to combine potential needs to new business. This "feedback of thinking" is the second serendipity.

\section{Definition of Intermediary Organization}

Intermediary organizations that possess the serendipity capability can find business opportunities by generating applications of technology to markets and exposing the potential needs of this market and meets those needs with causal loop between its stock of knowledge and search of facts. This fact suggests that this type of result is not purely accidental. The authors define this phenomenon as serendipity capability, something that plays the role of business creation by intermediary organizations. Serendipity is way of finding social issues (i.e. potential needs). Intermediary organizations should possess following characteristics to exploit serendipity:

(1) It collects information about every industry and accumulates it as knowledge;

(2) It has strong ties with user companies in market;

(3) It can check with market players to learn the validity of potential needs.

\section{Finding Potential Needs and/or Market by Using Serendipity}

According to Merton (1949), serendipity is a particular experience, and accidental findings are accumulated as knowledge through the searching out facts. In Figure 6, it can find relation of particularly important business phases and serendipity. Additionally, Table 4 indicates the flow of events in serendipity. The first serendipity - finding opportunity, finds opportunity by exploiting awareness. "Search of fact" combines core technology or specific resources with potential needs or social issues. "Stock of knowledge" solves social issues or realizes potential needs by exploiting accumulated knowledge and/or information. "Stock of knowledge" accumulated by "search of facts" has formed a causal loop to return to serendipity. Serendipity iterates through loops of combining with thought and potential needs have formed into something more concrete.

Table 4

Flow of Event on Serendipity

\begin{tabular}{|l|l|}
\hline Particular & Contents \\
\hline Finding opportunity & Find opportunity by exploiting awareness. \\
\hline Search of facts & Combine core technology or specific resources with potential needs or social issues. \\
\hline Stock of knowledge & Solve social issues or realize potential needs by exploiting accumulated knowledge and/or information. \\
\hline
\end{tabular}




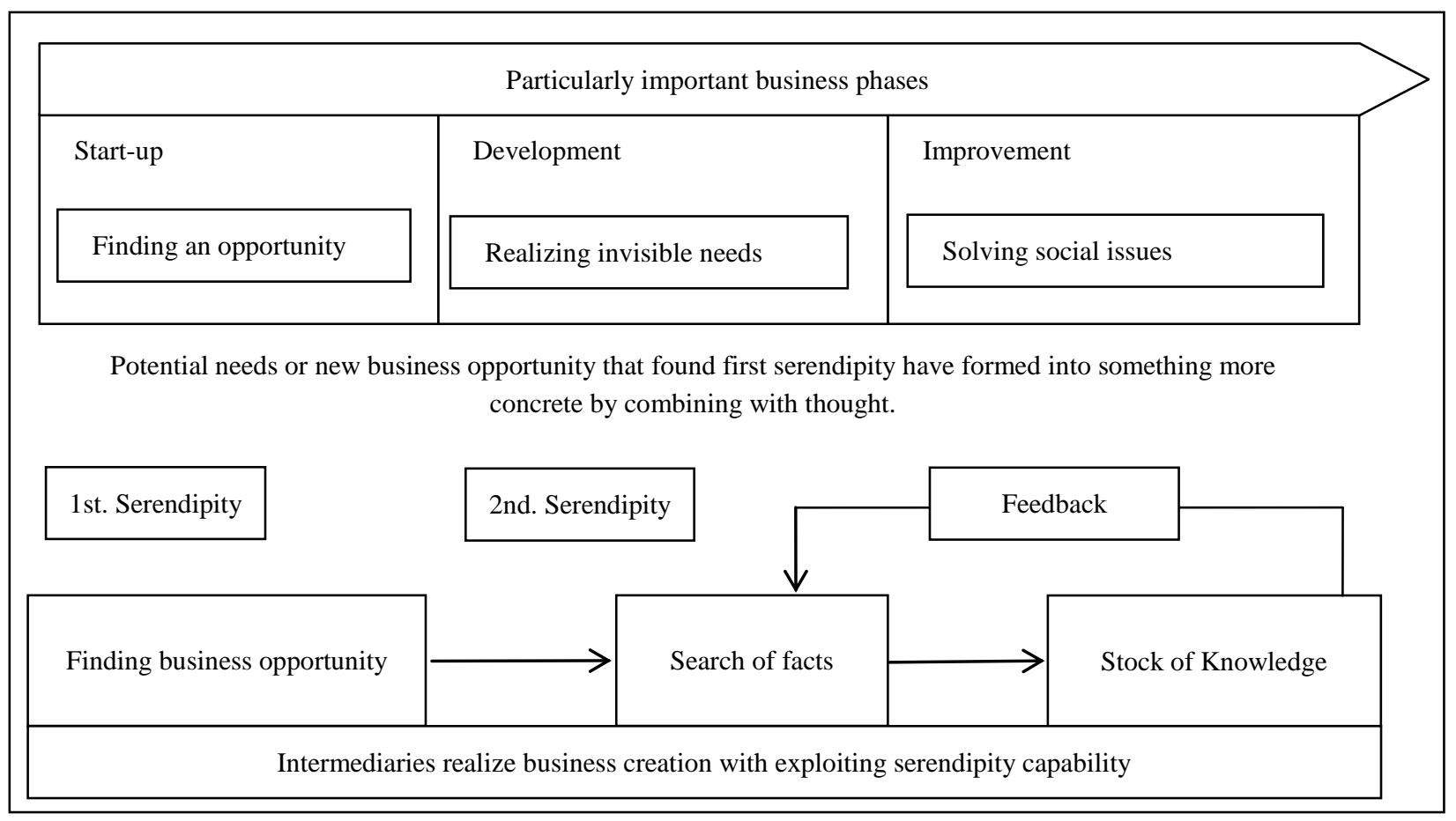

Figure 6. Relation of particularly important business phases and serendipity.

\section{Conclusions}

This study clarifies how serendipity capability is effective in carrying out business creation beyond the start-up, development, and improvement phases. The authors consider specific capability to be able to find potential needs or business opportunities by exploiting awareness, and this specific capability is defined as serendipity capability in this paper. Serendipity is a capability that finds social opportunity (i.e. potential needs) and can combine resources, and additionally exposes potential issues and solves them via feedback loops of thought.

Challenge for the future is to examine experimental proof of the effectiveness of serendipity through other case studies.

\section{References}

Andel, P. V. (1994). Anatomy of the unsought finding: Serendipity: Origin, history, domains, traditions, appearances, patterns and programmability. British Journal for the Philosophy of Science, 45(2), 631-648.

Axell Corporation. (2000-2013). Investor relations (IR). Retrieved from http://www.axell.co.jp/jp/index.html

Bühler, K. (1990). Theory of language: The representational function of language. Amsterdam: John Benjamins Publishing company.

Cristiforo, A. (2000). Peregrinaggio di tre giovani figliuoli del re di serendippo. Roma: Salerno Editrice S.r.1..

Eisenhardt, E. M. (1989). Building theories from case-study research. Academy of Management Review, 14(4), 532-550.

Eisenhardt, K. M. (1991). Better stories and better constructs: The case for rigor and comparative logic. Academy of Management Review, 16(3), 620-627.

Eisenhardt, K. M., \& Graebner, M. E. (2007). Theory building from cases: Opportunities and challenges. Academy of Management Journal, 50(1), 25-32.

Glaser, B. G. (1992). Basics of grounded theory analysis: Emergence vs. forcing. Mill Valley: Sociology Press.

Glaser, B. G., \& Strauss, A. L. (1967). The discovery of grounded theory: Strategies for qualitative research. New York: De Gruyter. 
Granovetter, M. S. (1973). The strength of weak ties. American journal of sociology, 78, 1360-1380.

Hamel, G., \& Prahalad, C. K. (1990). The core competence of the corporation. Watertown: Harvard Business Publishing.

Hannan, P. J. (2006). Serendipity. Bloomington: iUniverse self-publishing company.

JASVA Research Report. (2007). JAPAN semiconductor, FPD venture comprehensive list, Japan semiconductor ventures association (JASVA). Retrieved from http://www.jsena.org/jasva/jasva.htm

Kuhn,T. S.(1962). The structure of scientific revolutions. Chicago: Chicago Press.

Martin, P. Y., \& Turner, B. Y. (1986). Grounded theory and organizational research. The Journal of Applied Behavioral Science, 22(2), 141-157.

Merton, R. K. (1949). Social theory and social structure. Glencoe: The Free Press.

Merton, R. K., \& Elinor, B. (2003). The travels and adventures of serendipity: A study in sociological semantics and the sociology of science. Princeton: Princeton University Press.

Nagai, A., \& Tanabe, K. (2007). The enabler role of Japan's semiconductor distributors-linking technology with market needs. Journal of Japan Society for Intellectual Production, 6(1), 23-33.

Nagai, A., \& Tanabe, K. (2011). Sharing and using of secret information for collaborative innovation: Case study on development of ASSPs. Development Engineering, 30(2), 133-142.

Remer, T. G. (1965). Serendipity and the three princes: From the Peregrinaggio of 1557. Norman: University of Oklahoma Publishing.

Roberts, R. M. (1989). Serendipity: Accidental discoveries in science. Weinheim: Wiley-VCH Verlag GmbH \& Co.

Ronald, S. L. (1985). Educating for the serendipitous discovery. Journal of Chemical Education, 62(4), 282-285.

Sawaizumi, S., Shiose, T., Kawakami, H., \& Katai, O. (2005). The use of serendipity for discoveries (Workshop on intelligent and evolutionary systems (IES2005)).

Stein, S. (1999). Archimedes: What did he do besides cry Eureka. Washington, D.C.: Mathematical Association of America.

Umberto, E. (1999). Serendipities: Language and lunacy. New York: Columbia University Press.

Walpole, H. (1954). Horace Walpole's correspondence with Sir Horace Mann. New Haven: Yale University Press.

Yin, R. K. (1981). The case study crisis: Some answers. Administrative Science Quarterly, 26, 58-65.

Yin, R. K. (1994). Case study research: Design and methods (2nd ed.). Newbury Park: Sage. 